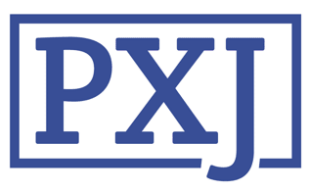

Patient Experience Journal

Volume 8 | Issue 1

Article 2

2021

\title{
The paradoxical injunctions of partnership in care: Patient engagement and partnership between issues and challenges
}

\author{
Khayreddine Bouabida \\ University of Montreal \\ Marie-Pascale Pomey \\ University of Montreal \\ genevieve Cyr \\ University of Montreal \\ Ursulla Aho-Glele \\ University of Montreal \\ Breitner Gomes Chaves \\ University of Montreal
}

Follow this and additional works at: https://pxjournal.org/journal

Part of the Health and Medical Administration Commons, Health Policy Commons, Health Services Administration Commons, and the Health Services Research Commons

\section{Recommended Citation}

Bouabida K, Pomey M, Cyr g, Aho-Glele U, Gomes Chaves B. The paradoxical injunctions of partnership in care: Patient engagement and partnership between issues and challenges. Patient Experience Journal. 2021; 8(1):5-12. doi: 10.35680/2372-0247.1538.

This Commentary is brought to you for free and open access by Patient Experience Journal. It has been accepted for inclusion in Patient Experience Journal by an authorized editor of Patient Experience Journal. 


\section{The paradoxical injunctions of partnership in care: Patient engagement and partnership between issues and challenges}

\section{Cover Page Footnote}

This article is associated with the Patient, Family \& Community Engagement lens of The Beryl Institute Experience Framework (https://www.theberylinstitute.org/ExperienceFramework). You can access other resources related to this lens including additional PXJ articles here: http://bit.ly/PX_PtFamComm 


\title{
The paradoxical injunctions of partnership in care: Patient engagement and partnership between issues and challenges \\ Khayreddine Bouabida,University of Montreal, khayreddine.bouabida@umontreal.ca \\ Marie-Pascale Pomey, University of Montreal,marie-pascale.pomey@umontreal.ca \\ Genevieve Cyr, University of Montreal, genevieve.cyr.2@umontreal.ca \\ Ursulla Aho-Glele, University of Montreal, ursulla.aho-glele@umontreal.ca \\ Breitner Gomes Chaves, University of Montreal,breitner.gomes.chaves@umontreal.ca
}

\begin{abstract}
Partnership in care and patient engagement is an expanding approach and tremendously promising for improving the quality of healthcare services. However, the approach could be subject to many issues and challenges of various kinds. In this paper, we develop a reflection of the challenges and issues that the approach of patient engagement and partnership in care is facing. After a brief presentation of certain key concepts of partnership in care and patient engagement, we discuss in this paper the most worthy of consideration issues that we identified and classified as follows: Political, Financial, Organizational, Clinical, and Ethical Issues. We then conclude the paper with certain recommendations that may help to better deal with those challenges and issues and alleviate their impacts.
\end{abstract}

\section{Keywords}

Patient engagement, partnership in care, patient experience, quality of care, issues and challenges, ethical dilemmas

\section{Introduction}

Over the past decade, patient engagement and partnership (PEP) has experienced unprecedented success, and many health system specialists see its integration as an essential strategic approach to improving the quality of care provided by health systems. ${ }^{1,2,3}$ Growing efforts are being made to integrate patients in many areas in order to improve or rethink care services, strategies, and policies by integrating patient experiential knowledge. ${ }^{4,5,6}$ Caregivers, leaders, and researchers have come to realize that solutions to healthcare issues cannot be found in the absence of patients, users, and their loved ones. They all agree today that the participation of patients is an avenue capable of providing great support to the healthcare system.5,6,7,8,9 For the past decade, research studies and interventions on engaging patients and their families in different levels of the healthcare system have been multiplying in order to develop PEP models and strategies allowing to improve the quality of care services but also to ensure better financial allocation through the adoption of well-founded strategic choices and well-oriented health policies. $5,6,7,8,9$

The appearance of the intriguing book ${ }^{6}$ entitled "Patient Engagement: How patient-provider partnerships transform healthcare organizations" edited by Pomey, Denis, and Dumez, three experts internationally renowned in the field, has prompted us to reflect on the issues and challenges facing the PEP approach. Indeed, by using the most relevant concepts of partnership in care (PC) explored and detailed by the three authors in this book, we came to develop an analytical overview of the most frequent and important issues and challenges facing the PEP approach. Although the PEP progress and the tremendous achievements that have been made by PEP so far are well-recognized by many healthcare gurus, ${ }^{6}$ many issues and challenges of various nature (organizational, political, economic, clinical, and ethical) started emerging in an accelerated way and are likely to slow down or even stop the remarkable progress of PEP. In this context, we develop a reflexive commentary to raise awareness of the main challenges that we believe PEP is facing. This synthesis is supported by certain concepts developed by Pomey, Denis, and Dumez (2019). In addition, the perspectives advanced in this paper are also supported by our experience and observation of multiple interventions while being active in the PEP field. Before proceeding to debrief and clarifying the issues and challenges of the PEP approach, we will first present certain important concepts that would help to understand the stakes and the challenges developed in this paper.

\section{Patient Engagement \& Partnership Concepts}

The concept of PEP aligns with the Partnership in Care (PC) concept. ${ }^{6,8,9,10}$ This concept encourages patients, families and loved ones, their representatives, and health professionals to working in active partnership and 
engaging at various levels across the healthcare system in order to promote an optimal partnership care experience, that enable patients to acquire a state of health in accordance with their own life project, and eventually to contribute to continuously improve the quality of provided care services. ${ }^{6,9,10,11,12,13}$ In fact, the PC approach was consolidated in 2010 at the Faculty of Medicine of the University of Montreal through a co-leadership of patients and health professionals to create an innovative and making-sense approach based on the principle of "doing with patients" in contrast of the classic approach of Patient and Family-Centered Care (PFCC) which was more focused on "doing for patients." 6 The foundation for Partnership in Care is based on the following elements, ${ }^{6}$ the need to:

1) Empower patients to make free and informed decisions.

2) Recognize the value of the experiential knowledge that one develops through the experience of living with disease and illness (including the use of different health services).

3) Develop one's skills throughout the care process.

4) Consider oneself as an actor of care and therefore as full members of one's care team.

5) Focus the objective of the care process on achieving one's overall life project rather than on a single curative objective that may be reductive and often unrealistic in the context of chronic disease.

Thus, the Montreal Model recognizes that patients acquire experience over time, leading to the development of skills that can be shared by participating in certain activities. 2,6 Indeed, patients develop knowledge about life with the disease, self-management abilities, and the use of health services. Once mastered, knowledge and skills can be put to use in various training activities (as Resource Patients in Education), activities improving the health and social services system (as Resource Patients in Healthcare), research projects (as Resource Patients in Research), and so on. 2,6,11 Considering this fact, the Montreal Model acknowledges distinct types of expert patients and therefore different functions and engagements (Figure 1), ${ }^{6}$ for instance: "Patient Advisors" (PA) are patients who wish to share their experience with other patients; "Patient Leaders/Coaches" are patients with significant experience from multiple care settings and who are able to support other individuals or groups can become Patient Leaders/Coaches; "Patients-as-Researchers" in research settings are patients who can be valued as "Experience Collectors," full members of the research team (action research) or contribute more broadly to reflections on the orientations of research institutions (co-design), and so on. ${ }^{2,6}$ Furthermore, these roles and functions can take place at different levels of healthcare. At the clinical level (micro-level), patients can intervene not only in their care, but also use their experience in advising other patients, or clinical teams on clinical issues. At the organizational level (meso-level), patients are involved with the management and coordination team and quality evaluation committees for organizing and evaluating healthcare services. In this context, since 2017 Accreditation Canada (AC) is officially conducting accreditation visits with patient partners being fully involved in the visit and accreditation process of healthcare organizations. At the strategic and policy level (macro-level), patients participate on the board of directors or in advisory groups to formulate policies, develop governance strategies, and budget allocation of the healthcare system. $6,10,11,12,13$

The Montreal model offers a continuum of strategic options in engaging and partnering with the patient that starts from information, consultation, collaboration, and goes until the co-design and shared leadership process. ${ }^{6,10,11,12,13}$ In terms of co-creation and coleadership, i.e., that when searching for solutions and implementing measures, patients are equally and jointly engaged in the same way as other professionals, which leads to equal shared responsibility among all actors. ${ }^{2,6}$

Finally, PEP is an approach that can be designed in many forms and used at different levels to achieve various goals. ${ }^{14,15}$ However, PEP can be subject to an array of problems and challenges which we will highlight and develop in the following section.

\section{Patient Engagement \& Partnership Issues and Challenges}

During our reflection on the most common issues characterizing the field of PEP, we have referred to the conceptual framework developed by Bernard Lo and Marilyn J. (2009) to base our judgment considering this framework as a relevant conceptual basis that has already received huge attention from the academic and professional medical sector. ${ }^{16}$ In fact, Bernard and Marilyn (2009) focused on analyzing the complex relationships that underlie the behavior and relationship interests between clinicians, researchers, and patients as well as other stakeholders such as managers and investors, and politics in the healthcare to identify the main issues in the practice and research in the medical field. ${ }^{16}$ Thus, based on certain perspectives developed in Bernard and Marilyn's (2009) conceptual framework that has determined and specified issues in medical practice and research, we were able to excerpt and identify issues and problems specific to PEP and assign them in distinct categories.

\section{Politics "Power Relationships"}

By politics issues, we refer to tensions and conflicts between the different groups within the sphere of PEP. Indeed, those politics issues arise through power dynamics and interests of stakeholders and actors concerned in one way or another by PEP programs and interventions. 
Figure 1. Roles, levels, and continuum of PEP2,6,10,11

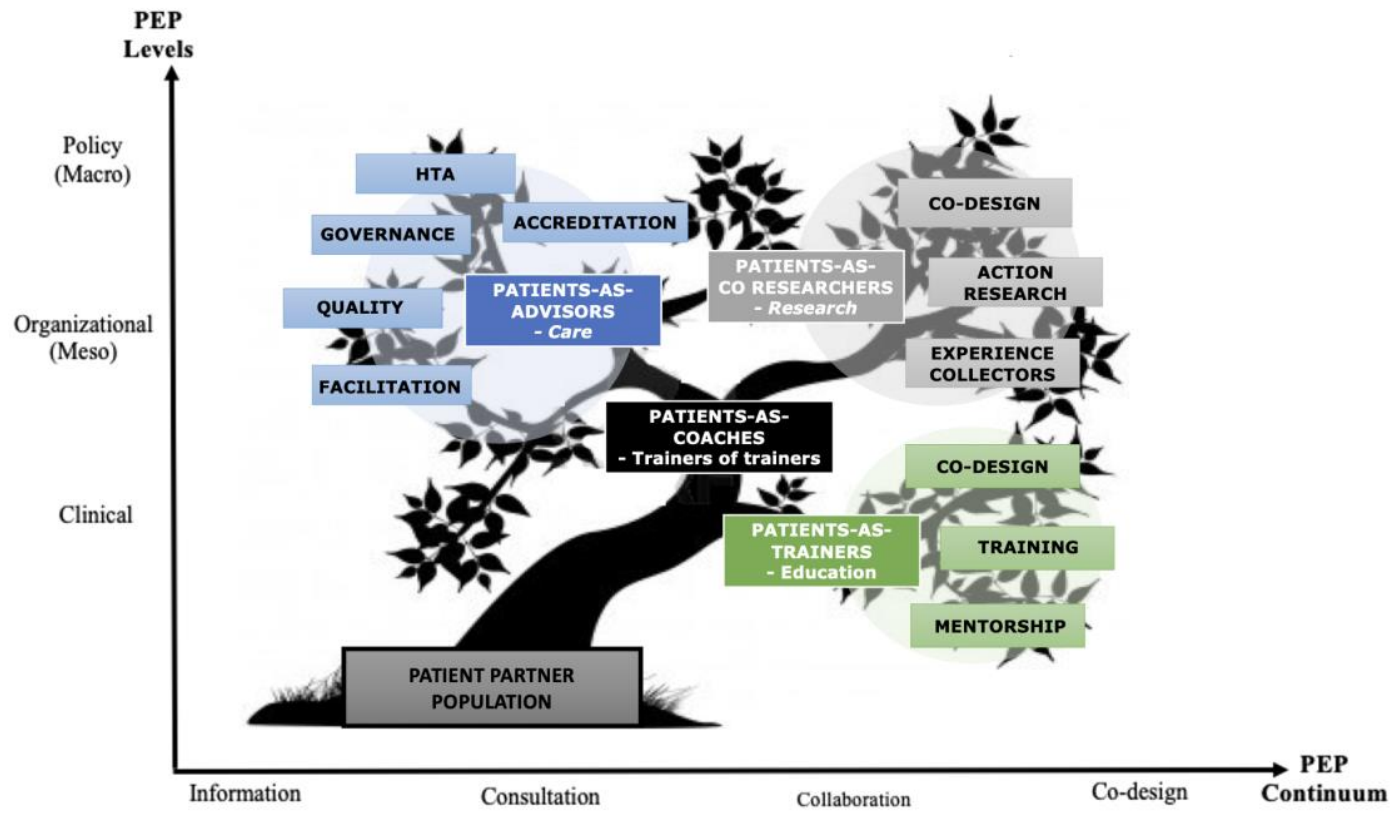

Through our analysis of the politics tensions between the different groups of the PEP sphere, we identified three groups.

The first group represents the group of resistors. In this group, we identified certain clinicians, doctors and nurses but also psychologists and social workers, who question the PEP approach hence do not display real support and adherence to PEP programs which affect the implementation of PEP programs. We assume that their attitude could be explained by a fear of having their interests threatened and power shared and eventually reduced, or because they are simply not convinced by scientific evidence of the effects of PEP that have been demonstrated so far in different studies. ${ }^{17,18,19,20,21,22,23}$ In this first group, we also find another type of professional displaying resistances, the middle managers and services leaders who sometimes oppose and resist PEP programs because of the importance of the work and the complex functioning processes generated by the implementation of PEP interventions and programs within care structures and services. ${ }^{18}$

The second group that we identified represents the advocates and promoters of the PEP approach who are very enthusiastic about everything related to PEP and who are favorable to introducing and engaging patients into many activities related to healthcare services. This group seems to be composed of many researchers and clinicianresearchers and patient partners but also doctors and nurses who are concerned about the humanity of health. The position of individuals in this group could be motivated by their own experience with a care trajectory during a period of their lives, or they have witnessed a care trajectory of their loved ones or because this ties in with their humanist values, and sometimes simply because they have been convinced by the studies' findings.

The third group identified represents the neutral individuals such as decision-makers and leaders from various health institutions, public health bodies and governmental structures, essentially the ministry of health. We believe this group should be resolving or at least attenuating the conflicts between the first two groups. That could be possible by formulating a clear policy in which it is specified how patients, researchers, health care providers, and decision-makers should actively collaborate altogether without letting a place for cleavage or political tensions. Also, the two groups should show a serious will to overtake their disagreement and find common ground for the interest of building a sustainable, accessible and equitable health care system.

There still remains a deepened work to accomplish to know the profiles of these parties, in order to understand them better, in particular, to determine their interests, objectives, resources, ideologies, and in order to figure out how to better work with them. To do so, studies could be conducted in multiple analytical and theoretical frameworks such as contingency theory and political theory, plus institutional theory ${ }^{24,25,26,27}$ can be mobilized. We believe that this type of analytical and theoretical framework would be very useful and a real asset to 
decipher these political tensions in order to find effective solutions to contain these tensions.

Finally, all the groups of actors including the cons are seeking to democratize healthcare, but at the same time they do not give all the necessary means to achieve it starting by recognizing a status and recognizing a contribution via remuneration or at least compensation for patient partners.

\section{Organizational}

Organizational problems refer to managing difficulties encountered in the implementation of PEP programs by organizational managers. The managers that have many responsibilities such as training their teams, ensure members' participation and work on evaluations and recognition of the accomplished work and so on. Knowing that many of the managers don't have necessarily a clinical background, but even for those who have a clinical background, they have to learn on how to interact with patients. The PEP programs obviously add work and tasks for all managers without actually recognizing or compensating for this overload and most of the time without training. Indeed, patient partnership programs in several cases constitute a real challenge for managers within care services because of the complexity of their implementation process but also of the monitoring and evaluation process. ${ }^{19}$ In fact, PEP program implementation requires robust operational mechanisms and methods supported by a dynamic system, flexible management and furthermore by real support from organizational leaders. ${ }^{19}$ The success of setting up PEP programs in care services rests mostly on the organizing capacities of these services in terms of strategic planning operational management, communication, coordination, and collaboration between the various stakeholders, structures throughout the partnership process, and on multiple facets throughout the design, the implementation and monitoring, and until the evaluation and recognition of these programs. ${ }^{31}$

Researchers and PEP experts should not focus only on PEP effects and impacts evaluation. Implementation studies on PEP programs have to develop and provide insights and smart implementation mechanisms and strategies in order to ease the feasibility and to guide managers in implementing PEP programs within their structures. Finally, of course, we shouldn't neglect or forget the need for training of managers and for patient partners not only on the technical dimensions but also on the interpersonal dimensions in order to establish a mutual understanding of the needs, objectives, and difficulties of each other to overcome the organizational challenges and problems. Courses for future managers have to include patient partnership methodology, coached with patients.

\section{Clinical}

By clinical issues, we are referring to the effects of changes in relationships and the effects of certain contextual dimensions on the clinical trajectory and quality of care process. Clinical issues in PEP programs can be a result of the contextual influence, i.e., that the influence of a problem of another nature, for example by the influence of lack of the resources and infrastructure, the influence of difficulties in managing care services, or by the influence of political tensions in healthcare services. Clinicians are used to being in a paternalistic (?) therapeutic relationship with patients, $7,8,10,12,13,15$ whereas in a PEP approach, they have to change their relational positioning with patients and consider them as an alter-ego, until considering them as "Partners" and therefore sharing a certain power with them which is not always appreciated by some clinicians. Clinical problems can also be the result of a simple misunderstanding in the therapeutic relationship between clinician and patient. $7,8,10,12,13,15$

Regarding the influence of the lack of resources and infrastructure, that means that clinical environments and services when PEP interventions are being implemented or conducted and or when clinicians are engaging patient partners to support other patients subject to clinical treatments, they don't find the necessary structures to receive and work with patient partners, in particular offices, meeting rooms, as well as a lack of IT tools and other devices for collaboration and group work. Those logistics problems sometimes leave clinical consequences especially on the emotional and psychological state of patients in need of patient advisors and peer support during their trajectory of treatments within several clinical services such as the reimplantation and rehabilitation, oncology, burns services, etc., where engaging patient advisors is highly suggested. ${ }^{32}$

Finally, the changeability of clinical teams and patient partners could also destabilize PEP programs. In fact, the clinical teams are constantly changing, in particular, the managers, which obliges the patients to constantly have to acclimatize to new people and in the other direction, the accompanying patients change which may consequently affect the conducting of the clinical process which goes against the clinical goals of the designed PEP program.

\section{Financial}

The budgets dedicated to PEP programs, whether for the organizational interventions or for research, represent a very small proportion compared to the budgets devoted to other programs, for instance, medical technology development programs, and artificial intelligence programs, or drug research and development. In Québec, for instance, the majority of PEP programs are publicly or charitably funded. Here again, PEP programs funded by private funds remain very rare compared to private funding injected into interventions and research and 
development projects on medical technologies, artificial intelligence, or drug manufacturing. It seems that PEP does not attract private donors and investors. Although, it is also true that the promoters of PEP programs, especially researchers, do not make much effort to find alternative sources to public funding. In order to promote PEP, it is necessary to create fundraising mechanisms, develop PEP promotion and marketing strategies in order to attract private donors, since public funds are limited and difficult to obtain due to the competitive nature of research funds. A very encouraging example of fundraising intelligence occurred at the Center of Excellence on Partnership with Patients and the Public (CEPPP) in Montreal where they succeeded to obtain funds from a private business. This fundraising strategy centered through private donors and private businesses could be developed in other PEP contexts.

It might be questioned why this economic difficulty would even be considered as a real issue; well, the answer would be as simple as we imagine. In fact, low funding seems to generate issues of a different nature. The lack of funding could contribute to provoking a serious ethical problem. ${ }^{28,29,30}$ In fact, the lack of sufficient funding in the field of PEP could push to exploitation and the instrumentalization of patient partners by depriving them of an official statute, fair compensation and sometimes even from reimbursement of the costs they paid out to participate or engage in PEP programs. ${ }^{28,30}$ The question of the remuneration of the patients is not the only effect associated to the financial issues; certain clinical and organizational challenges, which we are going to develop in the following part, also seem to be in connection with the lack of sufficient funding in the field of PEP. $28,29,30$

\section{Ethical}

Ethical issues have been highlighted in certain papers and increasingly observed in many PEP interventions and programs. ${ }^{28,29,30,33}$ The ethical question in PC seems to be a serious issue that specialists and experts should focus on. In the literature, numerous articles are regularly published and focus on the methods, strategies, effects, and advantages of PEP programs. However, there are very few studies on the ethical questions and ethical framing of partnership in care (PC). ${ }^{28}$ In the Canadian context and despite the boom of PEP programs in the country, there is no framework or ethical guide dedicated to PC and PEP programs. ${ }^{28,30,31}$ For instance, the Canadian Patient Engagement guide ${ }^{9}$ is considered as a national reference book on patient engagement and partnership in care which specifies the rules of the PC art, but it does not specify ethical rules and doesn't establish specific and clear ethical guidelines of the domain. ${ }^{6}$ Indeed, this book, like many papers in the field of PEP and PC, focuses on the tools, mechanisms of engagement and partnerships, the strategies, but above all, on the clinical results. Again, despite the positive effects and benefits that patient engagement may offer, it is undeniable that this approach is susceptible to deviations and perverse effects like any other program, innovation or technology used in healthcare for improvement purposes. Few articles have been published on ethical issues in PEP programs, among them, Montreuil (2019) and, Martineau (2020) have well synthesized, identified, and described the ethical issues in PC and PEP programs. ${ }^{28,30}$ The ethical challenges that we observed during our experiences and activities in the field of PEP and which have been highlighted in other papers, ${ }^{28,29,30,33}$ particularly by Montreuil (2019) and Martineau (2020), come together around the following fundamental questions: remuneration, recognition, instrumentalization, representativeness and tokenism.

The first ethical dilemma which raises an enormous incomprehension and many questions is that of remuneration. Recognition of the work done by patients partners (PP) and patients advisors (PA) should go through fair remuneration; however, remuneration risks "professionalizing" patients. That is, we need to be careful and find out if this is desirable and ethically legitimate, especially since it risks making them over-responsible. At the same time, it is not right to deprive them of an official statute that may minimize their role and not recognize their essential clinical contributions that have been suggested in many studies. ${ }^{18,29,33,34,35,36}$

The second ethical dilemma, to which we want to draw attention is that of instrumentalization. ${ }^{28,30}$ Unfortunately, PP and PA during certain interventions are used, and at times even manipulated, to achieve objectives that have nothing to do with beneficence, the democratization of care, and improvement of the quality of care. Some people take advantage of PEP programs and use patient partners just to improve their image and increase their popularity of influence or promote their reputation or even to obtain funding for their projects without really believing in the role and valuable contributions of PP and PA and defending their rights, nor believing to the principles and goals for which the partnership in care (PC) was founded.

Thirdly, the hiring and selection process of patient partners seems to raise many questions, in particular, the representativeness. ${ }^{28}$ Certain recruitment processes for PP and PA seem to be discriminatory and give the right to participate in PEP programs only for very specific profiles, by requiring, for instance, a high level of education, communication in both languages, comfortable in speaking in public, and technical skills, particularly in the use of connected tools, and so on. Obviously, those are very specific and even extreme requirements that not only create ethical misconduct but also do not democratize the care that may go against the principles of PC.

Furthermore, another ethical dilemma that raises many questions is the symbolic effect of patient participation 
known by the "tokenism." 28,30 In fact, in some cases, it seems that patients are engaged only for the form, i.e., giving a symbolic place to patients and a passive role during a participatory, or consultation and deliberation workgroup without actually integrating them into an interactive process. The most common example of this occurs in boards of directors where patients are neglected or barely considered. ${ }^{28,30}$ Knowing, that the democratization of care insists that the patient voice must not only be heard, but it must be listened to and so integrated.

Finally, our goal here is not to make an exhaustive list of ethical concerns but more to raise awareness on the ethical issues likely to happen in PC that we should seriously consider and carefully evaluate. Thus, we believe that ethical issues are a bigger concern than political, economic, and organizational issues. Indeed, the four problems mentioned thus far are important and undoubtedly constitute a real constraint to PEP programs' development, but the ethical issues, if unaddressed, are likely to threaten or potentially stop the progress and evolution of the PEP approach. In fact, if PEP programs have become a real trend in healthcare systems, it is thanks to the trust of the healthcare users, patients, and their loved ones, also by the charitable and integrity assurance that those programs give to decision-makers, healthcare leaders, and funding providers. However, if the ethical problems are increasingly present and never being solved, that risks jeopardizing the confidence of users, patients, and their loved ones but also risks losing the support from the taxpayers and government funding providers.

Therefore, through this comment, we would like to invite the specialists and experts to encourage research on the evaluation of ethical issues in the area of patient engagement and partnership in care. We believe that there is an imminent need for the development of guidelines and an ethical framework specific to PEP. The purpose of this comment is not to make a judgment but to bring forward reflection and draw attention to ethical principles in the various PEP practices. We are appealing to the formulation of an ethical guide to adapt the framework for PEP activities. Such an approach would help and support the continuous improvement and the development of the PEP programs initially created to improve the quality of care provided by health systems.

\section{Conclusion}

We believe that the issues exposed in this paper are interconnected, and one acts and/or influences the other in a more or less particular way and intensity. For instance, political conflicts seem to interfere with the funding process which slows down the PEP programs and obstructs resources and structures necessary for resolving organizational and clinical issues. Thus, the political tensions and financial constraints seem to be associated with the appearance of ethical issues, notably the question of compensation, recognition, and instrumentalization. Finally, these problems could occur at the different levels of PEP and at different phases of the PEP continuum. It is not possible to do a systematic matching of all and each type of issue that we have exposed in this paper to a specific level and phase of the continuum of PEP. We end our synthesis with a set of suggestions set that may help to deal with some of the issues that we exposed and get over certain barriers that may slow or even threaten the progress of the PEP approach:

1) Encourage investment in PEP programs, in particular by creating various and sufficient funding programs to use them in research, evaluation, and training on PEP approach.

2) Provide with sufficient organizational and clinical resources and structures but also technology tools to foster collaboration, communication, and training .

3) Develop and formulate an ethical framework specific to the PEP and PC domain and in which ethical guidelines are well established and clearly explained, i.e., specifying "what to do, how to do, when to do, and by who to do in PEP and PC.

4) Promote innovation and continuous improvement, develop new strategies, new action mechanisms, and new ethical, intelligent, sustainable, and human models.

5) Install a compromise-and-negotiation culture between the different actors to overcome conflicting relationships and focusing on common progress and development rather than on differences and divergence.

\section{References}

1. François, P. et Rhéaume, J. "Les systèmes de gestion de la qualit é des soins dans les hôpitaux du Québec"; Ruptures, revue interdisciplinaire en santé (2001); 8 (1), 6- 25

2. Flora, Luigi, et al. « Chapitre 3. L'application d'un modèle intégré de partenariat-patient dans la formation des professionnels de la santé : vers un nouveau paradigme humaniste et éthique de coconstruction des savoirs en santé », Journal international de bioéthique et d'éthique des sciences, vol. vol. 27, no. 1, 2016, pp. 59-72. https://doi.org/10.3917/jib.271.0059

3. Pomey, Marie-Pascale; Morin, Edith; Neault, Catherine; Biron, Veronique; Houle, Lise; Lavigueur, Louise; Bouvette, Guy; St-Pierre, Nicole; and Beaumont, Martin (2016) "Patient Advisors: How to implement a process for involvement at all levels of governance in a healthcare organization," Patient Experience Journal: Vol. 3 : Iss. 2 , Article 15. DOI: $10.35680 / 2372-0247.1134$ 
4. Pomey, Marie-Pascale; Hihat, Hassiba; Khalifa, May; Lebel, Paule; Néron, André; and Dumez, Vincent (2015) "Patient partnership in quality improvement of healthcare services: Patients' inputs and challenges faced," Patient Experience Journal: Vol. 2 : Iss. 1 , Article 6. DOI: $10.35680 / 2372-0247.1064$ https://pxjournal.org/journal/vol2/iss1/6

5. Vigneault, Karine; Higgins, Johanne; Pomey, MariePascale; Arsenault, Josée; Lahaie, Valérie; Mercier, Audrey-Maude; Fortin, Olivier; and Danino, Alain M. (2015) "Bringing patient advisors to the bedside: a promising avenue for improving partnership between patients and their care team," Patient Experience Journal: Vol. 2 : Iss. 2 , Article 4.

DOI: $10.35680 / 2372-0247.1101$

6. Pomey, Marie-Pascale, Jean-Louis Denis, and Vincent Dumez. 2019. Patient engagement: how patient-provider partnerships transform healthcare organizations. https://doi.org/10.1007/978-3-030-14101-1.

7. Carman K. L., Dardess P., Maurer M., Sofaer S., Adams K., Bechtel C., \& Sweeney J. (2013). Patient And Family Engagement: A Framework For Understanding The Elements And Developing Interventions And Policies. Health Affairs, 32(2), 223231. doi:10.1377/hlthaff.2012.1133

8. Pomey, Marie-Pascale \& Dumez, Vincent \& Boivin, Antoine \& Rouly, Ghislaine \& Lebel, Paule \& Berkesse, Alexandre \& Descoteaux, Annie \& Jackson, Mathieu \& Karazivan, Philippe \& Clavel, Nathalie. (2019). The Participation of Patients and Relatives in Quebec's Health System: The Montréal Model. 10.1007/978-3-030-14101-1_3.

9. Équipe d'action pour l'engagement des patients, 2018. Le Guide canadien de l'engagement des patients en matière de sécurité. Institut canadien pour la sécurité des patients. Dernière mise à jour : févier 2018. http://www.patientsafetyinstitute.ca/fr/toolsresource s/patient-engagement-in-patientsafetyguide/pages/default.aspx

10. Karazivan, Philippe et al. "The patient-as-partner approach in health care: a conceptual framework for a necessary transition." Academic medicine : journal of the Association of American Medical Colleges vol. 90,4 (2015): 437-41. doi:10.1097/ACM.0000000000000603

11. Pomey, Marie-Pascale et al. "Patients as partners: a qualitative study of patients' engagement in their health care." PloS one vol. 10,4 e0122499. 9 Apr. 2015, doi:10.1371/journal.pone.0122499

12. Pomey, Marie-Pascale et al. "Patients as partners: a qualitative study of patients' engagement in their health care." PloS one vol. 10,4 e0122499. 9 Apr. 2015, doi:10.1371/journal.pone.0122499

13. Vincent, Charles, and René Amalberti. Safer Healthcare: Strategies for the Real World. 2016. Heidelberg New York Dordrecht London: Springer Cham.
14. Bombard Y., Baker R., Orlando E., Fancott C., Bhatia P., Onate K., Denis J-L., Pomey M-P. (2014). Engaging patients to improve quality care: A systematic review. BMJ Quality \& Safety, 0034(03).

15. Pomey M-P., Hihat H., Khalifa M., Lebel P., Néron A., and Dumez V., (2015). Patient partnership in quality improvement of healthcare services: Patients' inputs and challenges faced. Patient Experience Journal, 2(1), 1-16. Retrieved from http://pxjournal.org/journal/vol2/iss1/6

16. Institute of Medicine (US) Committee on Conflict of Interest in Medical Research, Education, and Practice; Lo B, Field MJ, editors. Conflict of Interest in Medical Research, Education, and Practice. Washington (DC): National Academies Press (US); 2009. Summary. Available from: https://www.ncbi.nlm.nih.gov/books/NBK22926/

17. Baker, G Ross et al. "Designing effective governance for quality and safety in Canadian healthcare." Healthcare quarterly (Toronto, Ont.) vol. 13,1 (2010): 38-45. doi:10.12927/hcq.2013.21244

18. Clavel, N., Pomey, M. \& Ghadiri, D.P.(. Partnering with patients in quality improvement: towards renewed practices for healthcare organization managers?. BMC Health Serv Res 19, 815 (2019). https://doi.org/10.1186/s12913-019-4618-8

19. Doyle C, Lennox L, Bell D. A. (2013). systematic review of evidence on the links between patient experience and clinical safety and effectiveness. BMJ Open;3:e001570. doi:10.1136/bmjopen-2012- 001570

20. Johnson, Sonia et al. "Peer-supported selfmanagement for people discharged from a mental health crisis team: a randomised controlled trial.” Lancet (London, England) vol. 392,10145 (2018): 409-418. doi:10.1016/S0140-6736(18)31470-3

21. Lloyd-Evans, B., Mayo-Wilson, E., Harrison, B. et al. A systematic review and meta-analysis of randomised controlled trials of peer support for people with severe mental illness. BMC Psychiatry 14, 39 (2014). https://doi.org/10.1186/1471-244X-14-39

22. Boivin, Antoine et al. "What are the key ingredients for effective public involvement in health care improvement and policy decisions? A randomized trial process evaluation." The Milbank quarterly vol. 92,2 (2014): 319-50. doi:10.1111/1468-0009.12060

23. Tantchou Dipankui, Mylène, et al. « La participation des patients à l'évaluation des mesures alternatives à la contention et à l'isolement », Santé Publique, vol. vol. 26, no. 2, 2014, pp. 217-226.

24. Rouleau, L. (2007). Théories des organisations. Approches classiques, contemporaines et de l'avantgarde. Québec : Presses Universitaires du Québec.

25. Scott R., Michael A., Smith K.G., (2004). Institutional Theory: Contributing to a Theoretical Research Program, In Great Minds in Management: The 
Process of Theory Development. Hitt, eds. Oxford UK: Oxford University Press.

26. Contandriopoulos A.-P. (2003a). Inertie et changement. Ruptures, revue transdisciplinaire en santé, 9(2), 4-31., revue transdisciplinaire en santé, 1(1), 8-26.

27. Begun James W., B. Z., Kevin Dooley,. (2003). Health Care Organizations as Complex Adaptive Systems. Advances in Health care Organization Theory, 253-288.

28. Montreuil, Marjorie et al. "Exploring Ethical Issues Related to Patient Engagement in Healthcare: Patient, Clinician and Researcher's Perspectives." Journal of bioethical inquiry vol. 16,2 (2019): 237-248. doi:10.1007/s11673-019-09904-6

29. Johnson, Karin E et al. "Promoting Patient and Family Partnerships in Ambulatory Care Improvement: A Narrative Review and Focus Group Findings." Advances in therapy vol. 33,8 (2016): 1417-39. doi:10.1007/s12325-016-0364-z

30. Martineau, Joé T et al. "Partnering with patients in healthcare research: a scoping review of ethical issues, challenges, and recommendations for practice." BMC medical ethics vol. 21,1 34. 11 May. 2020, doi:10.1186/s12910-020-0460-0

31. Lucian Leape Institute de la National Patient Safety Foundation. (2014). Safety Is Personal: Partnering with Patients and Families for the Safest Care. Retrieved from Boston (MA):

32. - Pomey MP, Efanov JI, Arsenault J, Mercier AM, Lahaie V, Fortin O, Haineault M, Danino AM. The Partnership Co-Design Lab: Co-constructing a Patient Advisor Programme to increase adherence to rehabilitation after upper extremity replantation. JHD. 2018;3(1):94-101. https://doi.org/10.21853/JHD.2018.38

33. Wilson, Elena et al. "Ethical Challenges in Community-Based Participatory Research: A Scoping Review." Qualitative health research vol. 28,2 (2018): 189-199. doi:10.1177/1049732317690721

34. Bush, Paula L et al. "Organizational participatory research: a systematic mixed studies review exposing its extra benefits and the key factors associated with them." Implementation science : IS vol. 12,1 119. 10 Oct. 2017, doi:10.1186/s13012-017-0648-y

35. Barello, S., G. Graffigna, and E. Vegni. 2012. Patient engagement as an emerging challenge for healthcare services: Mapping the literature. Nursing Research and Practice Nursing Research and Practice 2012(2): $1-7$.

36. Määttä, Sylvia et al. "Contract theories and partnership in health care. A philosophical inquiry to the philosophy of John Rawls and Seyla Benhabib." Nursing philosophy : an international journal for healthcare professionals vol. 18,3 (2017): 10.1111/nup.12164. doi:10.1111/nup.12164 